Pacific Journal of Mathematics

LOGARITHMIC CONVEXITY RESULTS FOR HOLOMORPHIC 


\title{
LOGARITHMIC CONVEXITY RESULTS FOR HOLOMORPHIC SEMIGROUPS
}

\author{
Keith Miller
}

The classical logarithmic convexity inequality, for solutions of $u^{\prime}=-A u$ with $A$ a self adjoint operator on Hilbert space, yield that $u$ is small at intermediate times, $0<t \leqq T$, provided that $u$ is small at $T$ and bounded at 0 . Use of the Carleman inequality for analytic functions allows one to easily generalize this result to the case of operators $A$ which are generators of holomorphic semigroups on Banach space.

The basic logarithmic convexity result states that $\log \|u(t)\|$ is a convex function of $t$ for solutions of the ordinary differential equation on Hilbert space, $u^{\prime}=-A u$, where $A$ is a self adjoint operator. The simplest and earliest proof known to the author appears in [1]; it involves merely differentiating $\log \|u(t)\|$ twice and use of symmetry and the Cauchy-Schwartz inequality.

Log convexity is equivalent to the following inequality: if $0 \leqq t \leqq T$,

$$
\|u(T)\| \leqq \epsilon, \quad\|u(0)\| \leqq E, \text { then }\|u(t)\| \leqq \epsilon^{t / T} E^{1-t / T}
$$

It thus provides a stability estimate for the problem of backward solution of $u^{\prime}=-A u$ with a prescribed bound, for if $u$ and $v$ are two solutions to this equation, both closely fitting measured data $g$ at time $T$ and satisfying prescribed bounds at time 0 ; i.e.,

$$
\begin{array}{cl}
\|u(T)-g\| \leqq \epsilon, & \|v(T)-g\| \leqq \epsilon \\
\|u(0)\| \leqq E, & \|v(o)\| \leqq E,
\end{array}
$$

then at intermediate times we have

$$
\|u(t)-v(t)\| \leqq 2 \epsilon^{t / T} E^{1-t / T}, \quad 0 \leqq t \leqq T .
$$

We wish to show that the basic log convexity inequality (1) generalizes quite easily, by use of the Carleman inequality, to the class of operators $A$ on Banach space which are generators of holomorphic semigroups. Such operators are usually defined in terms of existence and certain bounds for the resolvent operator $(A-z I)^{-1}$ in certain sectors of the complex plane, see Kato [4], or see Friedman [2] for a 
more concise and introductory treatment. From these bounds it follows that there exist constants $M \geqq 1, k$ real, and $0<\psi \leqq \pi / 2 k$ such that:

(4) (i) $A$ generates a semigroup $e^{-\tau A}$ which is strongly continuous at $\tau=0$ and satisfies the semigroup property, not only for real $\tau$, but also for all complex $\tau=t+i s$ in the closure of the sector $\Gamma_{\psi}=\{\tau \neq 0$ : $\arg \tau<\psi\}$,

(ii) $e^{-\tau A}$ is analytic with respect to $\tau$ in $\Gamma_{\psi}$,

(iii) $\left\|e^{-\tau A}\right\| \leqq M e^{k t}$ on $\bar{\Gamma}_{\psi}$.

This is a particularly large and interesting class of operators. It includes, for example (see [2]), essentially all elliptic operators on $L^{2}(\Omega)$ corresponding to zero Dirichlet data on $\partial \Omega$ for which the Gärding inequality applies, and all elliptic operators on $L^{p}(\Omega)$ corresponding to regular elliptic boundary value problems.

In the Hilbert space case it suffices that $A$ be a "sectorial operator," i.e.,

(5) (i) the numerical range of $A$ lies in the sector $\{z: \arg (z+k) \leqq$ $\pi / 2-\psi)$,

(5) (ii) $A$ is closed,

(5) (iii) the resolvent $(A-z I)^{-1}$ exists at at least one point $z$ outside this sector. Under these hypotheses (4) holds with $M=1$.

THEOREM. Let $A$ be the generator of a holomorphic semigroup on Banach space, with corresponding $M \geqq 1,0<\psi \leqq \pi / 2,0<\psi \leqq \pi / 2$, and real $k$, in (4). Let $u(t)$ be a solution of the ordinary differential equation $u^{\prime}=-A u$ (that is, $u(t)=e^{t A} u(0), t \geqq 0$ ) satisfying

$$
\|u(T)\| \leqq \epsilon,\|u(0)\| \leqq E .
$$

Then

$$
\|u(t)\| \leqq M e^{k(t-T w(t))} \epsilon^{w(t)} E^{1-w(t)}, \quad 0 \leqq t \leqq T,
$$

where $w(\tau)$ is the harmonic function on the "bent strip"

$$
S=\{\tau=t+i s:|\arg \tau|<\psi,|\arg (\tau-T)|>\psi\}
$$

which is bounded and continuous on $\bar{S}$, and which assumes the values 0 and 1 respectively on the left and right hand boundary arcs of $S$. 
Proof. It suffices to assume that $k=0$, for the general case then follows by considering $e^{-k \tau} u(\tau)$ instead of $u(\tau)$ itself.

The vector valued function $u(\tau)=e^{-\tau A} u(0)$ is analytic on $S$, continuous and bounded on $\overline{\mathrm{S}}$, and bounded in norm by $M E$ and $M \epsilon$ respectively on the left and right hand boundary arcs of $S$. The same conditions then hold for the complex valued function $f(\tau)=v^{*}(u(\tau))$, where $v^{*}$ is any element of unit norm in the dual Banach space. The Carleman inequality (whose proof after all merely involves dominating the subharmonic function $\log |f(z)|$ by the harmonic function $(\log \epsilon) w(z)+(\log E)(1-w(z))$, see [3]) then yields that

$$
\mid f(\tau) \leqq \epsilon^{\omega(\tau)} E^{1-w(\tau)} \quad \text { on } \quad \bar{S} .
$$

Since the norm of a vector $u$ is the supremum of its values $\left|v^{*}(u)\right|$ over all $v^{*}$ of unit norm, we obtain (7) as desired.

Remark. Notice that when $A$ is self-adjoint and semi-bounded from below, then the numerical range of $A$ lies on the segment $[-k, \infty)$ of the real axis, $\psi=\pi / 2, S$ is the vertical strip $\{\tau=t+i s$ : $0<t<T\}, w(\tau) \equiv t / T$, and we hence obtain (1) as a special case of (7).

\section{REFERENCES}

1. S. Agmon and L. Nirenberg, Properties of solutions of ordinary differential equations in Banach space, Comm. Pure Appl. Math., 16 (1963), 121-239, see p. 163.

2. A. Friedman, Partial Differential Equations, Holt, Rinehart and Winston, New York, 1969, see Chapter II.

3. A. Gorny, Contribution à l'étude des fonctions derivables d'une variable réelle, Acta Math., 71 (1939), 317-358, see p. 346.

4. T. Kato, Perturbation Theory for Linear Operators, Springer-Verlag, Berlin, 1966, see pp. 487-490.

Received July 25, 1974.

UNIVERSITY OF CALIFORNIA, BERKELEY 



\section{PACIFIC JOURNAL OF MATHEMATICS}

\section{EDITORS}

RICHARD ARENS (Managing Editor)

University of California

Los Angeles, California 90024

\section{J. DugundJI}

Department of Mathematics University of Southern California Los Angeles, California 90007

D. Gilbarg and J. Milgram

Stanford University

Stanford, California 94305

\section{ASSOCIATE EDITORS}
E. F. BECKENBACH
B. H. NeumanN
F. WoLF
K. YoshiDA

\section{SUPPORTING INSTITUTIONS}

\author{
UNIVERSITY OF BRITISH COLUMBIA \\ CALIFORNIA INSTITUTE OF TECHNOLOGY \\ UNIVERSITY OF CALIFORNIA \\ MONTANA STATE UNIVERSITY \\ UNIVERSITY OF NEVADA \\ NEW MEXICO STATE UNIVERSITY \\ OREGON STATE UNIVERSITY \\ UNIVERSITY OF OREGON \\ OSAKA UNIVERSITY
}

\author{
UNIVERSITY OF SOUTHERN CALIFORNIA \\ STANFORD UNIVERSITY \\ UNIVERSITY OF TOKYO \\ UNIVERSITY OF UTAH \\ WASHINGTON STATE UNIVERSITY \\ UNIVERSITY OF WASHINGTON \\ AMERICAN MATHEMATICAL SOCIETY
}

The Supporting Institutions listed above contribute to the cost of publication of this Journal, but they are not owners or publishers and have no responsibility for its contents or policies.

Mathematical papers intended for publication in the Pacific Journal of Mathematics should be in typed form or offset-reproduced (not dittoed), double spaced with large margins. Underline Greek letters in red, German in green, and script in blue. The first paragraph or two must be capable of being used separately as a synopsis of the entire paper. Items of the bibliography should not be cited there unless absolutely necessary, in which case they must be identified by author and Journal, rather than by item number. Manuscripts, in duplicate, may be sent to any one of the four editors. Please classify according to the scheme of Math. Reviews, Index to Vol. 39. All other communications should be addressed to the managing editor, or Elaine Barth, University of California, Los Angeles, California, 90024.

100 reprints are provided free for each article, only if page charges have been substantially paid. Additional copies may be obtained at cost in multiples of 50 .

The Pacific Journal of Mathematics is issued monthly as of January 1966. Regular subscription rate: $\$ 72.00$ a year (6 Vols., 12 issues). Special rate: $\$ 36.00$ a year to individual members of supporting institutions.

Subscriptions, orders for back numbers, and changes of address should be sent to Pacific Journal of Mathematics, 103 Highland Boulevard, Berkeley, California, 94708.

PUBLISHED BY PACIFIC JOURNAL OF MATHEMATICS, A NON-PROFIT CORPORATION Printed at Jerusalem Academic Press, POB 2390, Jerusalem, Israel.

$$
\begin{gathered}
\text { Copyright (C) } 1975 \text { Pacific Journal of Mathematics } \\
\text { All Rights Reserved }
\end{gathered}
$$




\section{Pacific Journal of Mathematics}

\section{Vol. 58, No. $2 \quad$ April, 1975}

Zvi Artstein and John Allen Burns, Integration of compact set-valued functions . . . . . . . . . 297

Mark Benard, Characters and Schur indices of the unitary reflection group $[321]^{3} \ldots \ldots \ldots . .309$

Simeon M. Berman, A new characterization of characteristic functions of absolutely continuous

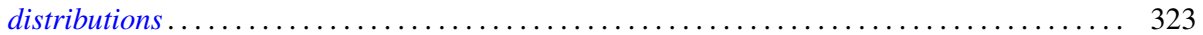

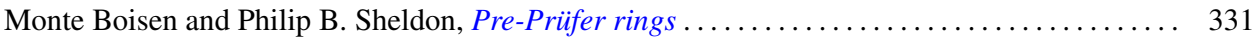

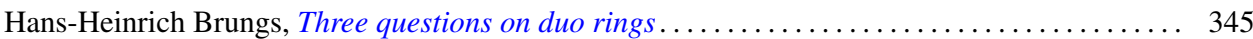

Iracema M. Bund, Birnbaum-Orlicz spaces of functions on groups................. 351

John D. Elwin and Donald R. Short, Branched immersions between 2-manifolds of higher

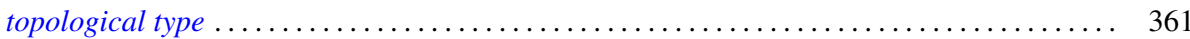

Eric Friedlander, Extension functions for rank 2, torsion free abelian groups . .......... 371

Jon Froemke and Robert Willis Quackenbush, The spectrum of an equational class of

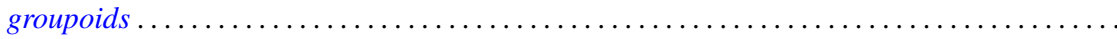

Barry J. Gardner, Radicals of supplementary semilattice sums of associative rings ...........

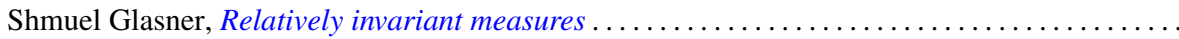

George Rudolph Gordh, Jr. and Sibe Mardesic, Characterizing local connectedness in inverse

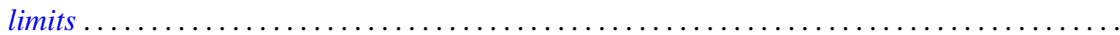

Siegfried Graf, On the existence of strong liftings in second countable topological spaces......

Stanley P. Gudder and D. Strawther, Orthogonally additive and orthogonally increasing

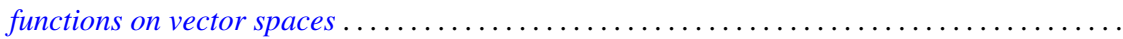

Darald Joe Hartfiel and Carlton James Maxson, A characterization of the maximal monoids and

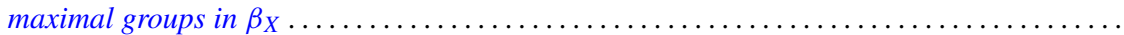

Robert E. Hartwig and S. Brent Morris, The universal flip matrix and the generalized faro-shuffle. .

William Emery Haver, Mappings between ANRs that are fine homotopy equivalences. .

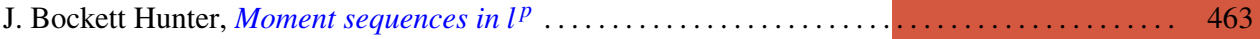

Barbara Jeffcott and William Thomas Spears, Semimodularity in the completion of a poset.... 467

Jerry Alan Johnson, A note on Banach spaces of Lipschitz functions . . . . . . . . . . . . 475

David W. Jonah and Bertram Manuel Schreiber, Transitive affine transformations on

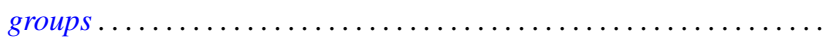

Karsten Juul, Some three-point subset properties connected with Menger's characterization of

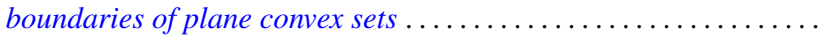

Ronald Brian Kirk, The Haar integral via non-standard analysis . . . . . . . . . . . . . 517

Justin Thomas Lloyd and William Smiley, On the group of permutations with countable

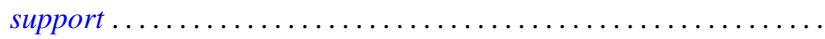

Erwin Lutwak, Dual mixed volumes .................................. 531

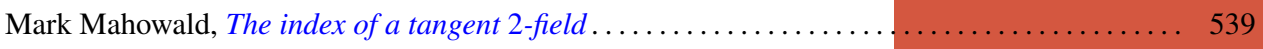

Keith Miller, Logarithmic convexity results for holomorphic semigroups . . . . . . . . . . . . 549

Paul Milnes, Extension of continuous functions on topological semigroups . . . . . . . . . . 553

Kenneth Clayton Pietz, Cauchy transforms and characteristic functions ................ 563

James Ted Rogers Jr., Whitney continua in the hyperspace $C(X) \ldots \ldots \ldots \ldots \ldots \ldots \ldots \ldots .569$

Jean-Marie G. Rolin, The inverse of a continuous additive functional . . . . . . . . . . . . 585

William Henry Ruckle, Absolutely divergent series and isomorphism of subspaces . ........ 605

Rolf Schneider, A measure of convexity for compact sets . ..................... 617

Alan Henry Schoenfeld, Continous measure-preserving maps onto Peano spaces .......... 627

V. Merriline Smith, Strongly superficial elements .......................... 643

Roger P. Ware, A note on quadratic forms over Pythagorean fields . . . . . . . . . . . . . . 651

Roger Allen Wiegand and Sylvia Wiegand, Finitely generated modules over Bezout rings . . . . 655

Martin Ziegler, A counterexample in the theory of definable automorphisms . . . . . . . . . 665 